\title{
Modes of knowledge and patterns of power
}

\author{
MAURICE KOGAN \\ Centre for the Evaluation of Public Policy and Practice, Brunel University, Uxbridge, \\ Middlesex UB8 3PH, England (phone: +44-207-226-0038; E-mail: \\ maurice.kogan@brunel.ac.uk)
}

\begin{abstract}
The paper attempts to identify the extent to which modes of knowledge can be associated with different patterns of and assumptions about power.

It discusses the meanings and scope of power itself, i.e. both within and beyond epistemic communities, as against 'social robustness' implying more democratic or inclusive forms of evaluation.

It analyses the extent to which knowledge has shifted from an internalist perspective relying on the prestige of epistemic communities towards socially relevant assumptions resting within social contexts. It discusses the factors affecting types of power patterns, such as: the nature of sponsors' objectives and the uses to which they might put knowledge; epistemic characteristics; the nature of the resource required, and the stage of finalisation reached. It sketches the range of models of sponsorship to which knowledge is subjected - from that of the free standing and autonomous individual through different patterns of sponsorship to the directly managed.

It attempts to link these classifications to a range of empirical examples, including the power of knowledge in government and in crossing the boundaries between universities and industry.

In discussing the reciprocal relationships between power and knowledge, it accepts that power affects the identification, use and transmission of knowledge. It is concerned, however, to question overdetermined perspectives of the relationships between knowledge and power whose mutual impacts may be strong but not easily predicted or defined.
\end{abstract}

Keywords: Knowledge, power, authority, epistemic, hermeneutics, finalisation.

\section{Introduction: The argument}

In social science we struggle hard to discover contingent relationships and, perhaps too often, confuse these with what are no more than partial and contestable associations. This paper attempts to note the extent to which knowledge and power may affect each other whilst noting that those interactions are less determinant than some analysts and social practitioners assume.

There are many discussions of the ways in which knowledge is shaped according to the field or tasks to which it is directed. This paper attempts to pick up one derivable theme from these concerns. It attempts to identify the extent to which modes of knowledge can be associated 
with different patterns of and assumptions about power. It discusses the meanings and scope of power, both within as well as beyond epistemic communities and its bases, e.g., belief in specialisation and peer evaluation, as against belief in "social robustness" (Nowotny et al. 2001) implying more democratic or inclusive forms of evaluation. It explores the range of knowledge modes, and analyses their links with forms of power. It attempts to establish the dynamics of those relationships and shows them to be multi-modal rather than simply contingent on each other. From there it can ruminate on particular examples drawn from governmental and policy practices.

The underlying argument is as follows. Specialist knowledge has intra-mural or internalist power. It is governed by accepted rules of certification within epistemic communities. Whitley (1984) argues that developments in scientific fields are driven by a shared concern of participants with the establishment and maintenance of their reputations, and hence that such fields can be described as "reputational work organizations"(pp. 25-29). But its second level of power is secular, and depends on the scientist being able to persuade the non-scientist that the work is useful or interesting. The converse might be true. Knowledge that rests on its appeal to the "shared meanings of given social communities" or "social robustness" might gain power with user groups and gain purchase within those who share its epistemic ideology. But it then might need to demonstrate sufficient of the test and demonstration features of hard science for it to be accepted as fully part of the scientific, intra-mural system.

These concerns are carried into two main example areas - the acceptance of research generated knowledge in government, and its impact across the university boundaries into industry and commerce.

\section{Meanings and scope of definitions of power}

Our starting point must be the meanings and scope of power itself. Do its defining characteristics entail any particular knowledge components or styles, or are its implications for knowledge more the result of operational or instrumental frames within which is enacted? In addressing the meaning of power, it will be necessary to divest ourselves of some over-simple assumptions, many of which emerge as dualities representing apparently contingent relationships. Thus, to take obvious examples to which we return more fully later, positivist forms of knowledge generation are held to be associated with determined and 
statist forms of government. That is not necessarily so. Again, knowledge is thought to be power, but, in fact, can also be disempowering, as when academics in the social sciences bar themselves from policy involvements by adopting critical stances.

For our purpose we need hardly differentiate power from authority, but note that they are closely connected; "the latter has a normative dimension, suggesting a kind of consent or authorisation, about which the former is similarly agnostic." (Isaac 2004, p. 54). The power of knowledge may indeed become authority, which we can take to be an institutional sub-set of power. One account offers three versions: authoritative institutions "reflecting the common beliefs, values, traditions and practices of members of society"; political authority "offering a co-ordination solution to a Hobbesian state of nature, or a lack of shared values"; and a third view which argues that "although social order is imposed by force, it derives its permanence and stability through techniques of legitimation, ideology, hegemony, mobilisation of bias, false consensus and so on which secure the willing compliance of citizens through the manipulation of their beliefs" (Philp 1992). These accounts, however, are less definitional than descriptive of the genesis and consequences of authority. Some of the broader definitions of power may be more useful.

Isaac's discussion of power records four models:

The voluntarist model, as described by Dahl, in which power is... "a capacity to get others to do what they otherwise would not do, to set things in motion and change the order of events." "Power terms ...refer to subsets of relations among social units such that the behaviour of one or more units... depend in some circumstances on the behaviour of other units..."

There are links between persuasive, voluntarist forms and the hermeneutic or communicative model. The hermeneutical model of power holds that it is constituted by the shared meanings of given social communities.

A structuralist model is rooted in the work of Marx and Darwin. It insists on the pre-given reality of structural forms that both enable and constrain human conduct. This leans towards power being vested in those who have command of the structures controlling knowledge formation and use.

In a post-modernist mode, as developed in Foucault (Foucault 1977) and some feminist writing, language and symbols are central to 
power. Power is defined as the capacity to act possessed by social agents in virtue of the enduring relations in which they participate... "It has a "materiality" deriving from its attachment to structural roles, resources, positions and relationships." This micro-analysis of the power exercised by different communities implies that knowledge is an exercise of power, which could be particularly exemplified by the power of academic disciplines.

The voluntarist model invites the point, relevant to our discussion, that some forms of power depend on persuasion. Persuasive forms of knowledge, depending on rhetorical strategies, are likely to be different in format and content from those that depend on sanctions for their acceptance.

The hermeneutical definition can be related to the way in which academic power is exercised. Within epistemic communities, power derives from specialisation and peer evaluation related to it. This justifies exclusiveness - the specialist possesses knowledge not available, or less available, to others. Those not empowered by specialised knowledge are excluded. Those within the peer group gain power and authority by their participation in the knowledge. In that sense, power is both a meaning shared within the group and an exclusive and esoteric meaning as far as those outside the group are concerned.

This is a perspective backed by Bourdieu (Bourdieu 1975): even the purest science is a "social field, with its own distribution of power and its monopolies, struggles and strategies, interests and profits." "The scientific field is the locus of a competitive struggle for the monopoly of scientific authority." The better resourced and the more autonomous the field, the more tightly drawn becomes the group of people that determine the holding of authority: i.e. the key competitors in the field. He thus not only distances himself from the idealised notion of scientific community but insists that "the operation of the scientific field itself produces and presupposes a specific form of interest."

Recent attempts to promote knowledge which rely on "social robustness" (Nowotny et al. 2001) imply more democratic or inclusive forms of evaluation, appealing to constituencies external to academe although this is, perhaps, more a programme for action than a statement of what now dominates the fields of knowledge. Much earlier, Trist (1972) argued that domain-based research represented a third category alongside basic and applied research. Domain-based, or policy-oriented, research is essentially interdisciplinary and the crossing of new boundaries and the creation of new syntheses may advance both 
knowledge and human betterment. It also entails wider reference groups, beyond the scientific or clinical communities. Lindblom (1990), as well, has articulated the case for demotic forms of 'probing' which would be set fair to demote the power of academic specialisation.

These power attributes can all yield some linkages with knowledge. The hermeneutical model, the more democratic or inclusive forms of evaluation, Lindblom's probing, Trist's domains, imply that the power that they generate may come through persuasion and interaction and their perceived utility. Both the voluntarist and structuralist models give space to the pressure exerted on the exercise of knowledge preferences by social structures such as academic status hierarchies or collegia. But that opens up the question of what kinds of knowledge will be more persuasive within these inclusive interactions, to which we will return later.

\section{The spectrum of knowledge}

Turning from power to our parallel concern, knowledge, there are several accounts of differences between different disciplines and areas of knowledge (e.g. Becher 1989; Braxton and Hargens 1996), of "the distinctions among...subdivisions of the academic profession which are due to the varied nature of their different subject-matters, and with the implications of these differences for the patterns of social organization and information-seeking behavior which characterize them" (Storer and Parsons 1968), of the ways subject matter characteristics may require particular forms of departmental organization (Biglan 1973), and of how different sorts of sciences become established and develop in different ways in different circumstances (Whitley 1977).

These are largely concerned with their internal characteristics, knowledge contents and shapings, rather than factors that might affect their relationships to power, particularly external power. Biglan (1973) set out to cross-correlate three subject matter dimensions (hard-soft, pure-applied, life-nonlife) with, among others, the degree of academics social connectedness. His concern was, however, primarily with intraacademic organisation rather than with those properties that generate or respond to the external exercise of power. For example, Biglan's use of "social connectedness" relates entirely to connections between different forms of scholarship rather than connections with the secular world. The masterly review of the literature provided by Braxton and Hargens (1996) does not venture outside the large enough concerns of 
what differentiates disciplines in terms of their academic content and forms of regulation.

These are discussions which throw light on the nature of power within academe. Some discussions also open the way, even if they do not travel the whole road, to connections with secular power. Becher's discussion of the wider contexts within which his academic tribes exist concludes that: "different epistemological categories can be seen to be associated with distinctive sets of relationships between the academic communities concerned and the wider contexts in which they subsist." (p. 148). Yet, this conclusion is more concerned with the impact of externalities on academe than on the power propensities of knowledge. Elzinga (1987) brings us nearer to the focus of this paper when he argues that "social and cognitive regulative structures interplay with each other...Truth-claiming activities are "at one and the same time social power-claiming activities in the real world of science in society." And his metaphor of "epistemic drift" (Elzinga 1985) i.e, of evaluative criteria, set an agenda for those concerned to detect the influence of sponsors on the objectives and mode of scientific research. Yet he, like Becher, does not pursue the issue of how far knowledge helps shape the exercise and locations of power.

For our purpose, which is more directly to assess the extent to which different forms of knowledge contribute to the power of institutions and individuals, we offer a spectrum of knowledge ranging from the "hard" and rigorously defined to "soft" forms which are less capable of meeting the criteria of being "explanations which are at once systematic and controllable by factual evidence" (Nagel 1961). In this, we in part follow the lead given by Storer $(1962,1972)$ (as related by Braxton and Hargens) who argued that disciplinary variations could be explained in terms of the underlying dimensions of "hard-soft" and pure-applied. Hardness is related to degrees of mathematicisation, agreement on the rules of research and the clarity of standards by which scholars can judge the importance of each other's work. Our simple spectrum is as follows:

HARD

$\begin{array}{llll}\text { Hard science } & \begin{array}{l}\text { Experiential/ } \\ \text { Connoisseurial }\end{array} & \begin{array}{l}\text { Hermeneutic } \\ \text { Phenomenological }\end{array} & \begin{array}{l}\text { Common sense (Nagel) } \\ \text { Ordinary Knowledge }\end{array}\end{array}$

Nagel sets the scene for the hard end of the spectrum: "The practice of scientific method is the persistent critique of arguments, in the light of tried canons for judging the reliability of the procedures by which evidential data are obtained, and for assessing the probative force of the 
evidence on which conclusions are based." Such "intemalist" models of science (i.e., those relying on exclusive, intramural governing arrangements) have exerted a powerful influence not only upon scientists but on those who have admiringly observed science's growth and strength. In the "internalist" view, science is an authoritative and self-regulating universe. The nature of scientific work, its evaluative criteria, its institutional norms and structures are regarded as logically connected and rooted in the relationship between science and the physical world. Science explains regularities of nature in laws that are "both as precise and as general as possible." The criteria of scientific merit are thus accuracy of observation and measurement, replicability of experimental work entailing rigour in design and control, validity and systematic importance or profundity of theory. The derivative and tightly interconnected technical and moral norms of logical consistency, emotional neutrality and impartiality are strongly embedded in Merton's classic statement of the four sets of "institutional imperatives" of modem science: universalism, communalism, disinterestedness and organised scepticism, and in the additional norms, identified by himself and others of, for example, originality, humility and independence (Merton 1957). In this list, be it noted, universalism and communalism are credited with belonging to the intramural versions of scientific power.

At the other end of the spectrum, there is Nagel's account of "common sense", and Lindblom and Cohen's ordinary knowledge (1979). Yet, if the "softer" forms of knowledge do not display "the organisation and classification of knowledge on the basis of explanatory principles" they may yet seek "to discover and to formulate in general terms the conditions under which events of various sorts occur, the statements of such determining conditions being the explanations of the corresponding happenings" (Nagel p. 13). They appeal, however, as much to the demotic and lay perceptions of what applies and what works as to any esoteric form of knowledge structure. Their appeal might grow as users and consumers demand more power.

\section{Moves towards persuasive forms of knowledge}

The nature of knowledge has been subjected to a procession of critical approaches which shift the emphasis from cognitive content to its social characteristics. Polanyi (1962) argued that the validity of scientists' work is enforced not by objective proof but by the exercise of responsible judgement. For Popper (1972) the power of science is rooted not in 
its outcomes but in its methods of putting its propositions to the test. The issues became further elaborated and the internalist perspective to some extent undermined by Kuhn's belief (1972) that paradigms challenging previous conceptions are determined not only cognitively but socially by disciplinary communities. And Mulkay (1979) went further and argued that recognition by the profession is the key objective of the scientist and that the scientific community was not a republic but a complex nexus of problem-focused, discipline-centred and wider networks of elites able to perpetuate themselves through interaction between differential allocation of resources, differential capacity to recruit the best talent, and a privileged informal communication system. With Kuhn and Mulkay, power rests not solely on epistemics but also on social arrangements.

The context of the analysis is thus one in which the salience of the concept of power, and particularly the power of knowledge, has been questioned through the sociology of knowledge and postmodernism itself an important example of the power of knowledge to change political relationships. Assumptions about both knowledge and power have shifted. Concepts of power have changed markedly since the 1960s when power and authority as exercised politically and socially faced a crisis of legitimacy. The venerable legitimacies have not been supplanted so much as paralleled by new ones. Knowledge may be authorised as much by its social robustness and relevance as by its epistemic containedeness. It can be derived from communicativeness which is central to the hermeneutic and experiential modes of knowledge, though some of those working in the hard sciences might question whether one can always have confidence in what is being communicated. Perhaps the knowledge that scores highest is that which is hard and tight, perhaps positivistic and quantitative in the social sciences, and/or which is geared to key public issues and explained through multiple media - the science of DNA would be an example.

\section{Factors affecting power-knowledge relationships}

The power generated by knowledge might thus be affected by three sets of characteristics. One concerns its persuasiveness and appeal to social utility. The second concerns who determines the objectives of enquiry researchers or government or industry. The third gets to the heart of our concerns, following Whitley (1977) and Weingart (1977), in relating the epistemic style and status of the research to its power. 
On communicativeness, first, Rip (1997) observes that the authority of basic science is legitimised by being fundamental and subject to rigorous testing, but also by the promises made of it. Industry shares the scientific view that basic science will yield results, a view shared by some of those participating in the UK Foresight Initiative (Henkel et al. 2000) who yet maintained that Foresight needed different forms of knowledge, both "hard" and "soft", derived from social as well as natural science.

On the objectives-setting dimension, research sponsored by government or industry is almost always governed by the objectives of those commissioning it, although they may be negotiated with the researchers persuasively suggesting lines of enquiry (Kogan and Henkel 1983, Gornitzka 2004). We return to this point later.

We must be cautious about making global assumptions about the connections with particular power connotations. For example, the styles attributed to positivist science - often used as a kind of liberal academic swear word- may be found in examples where knowledge has contributed to considerable human progress, including the reduction of privileged political or economic power. Medical epidemiological studies have been used to break rather than advance privileged hegemonies, as tobacco firms would ruefully agree. Whilst most educators would question the measurement and assessment of their performances against bench marks and numerical scores of outcomes, some forms of connoissseurial inspection could be too subjective and biased and exercised in favour of particular educational doctrines. The tradition of Blue Book exploration of social problems at the turn of the 20th Century was positivist in style but exercised the power of knowledge without any kind of institutional coercive framework. The knowledge was authoritative in that it could cause changes in behaviour, but it did so by persuasion on key public issues, and in doing so it dislodged authoritative hegemonies.

In the UK the return to positivism, which had begun to go into some reverse from the early 1900s in school policy, has been decisive. It has become possible for the state to "know" what are the constituents of good education or research, in schools and higher education, how to achieve them (through the pressures generated by outcome analysis, bench marking and associated rewards systems) and thus convert precise and quantified forms of knowledge into authoritative resource rewards and penalties. This assertion of arithmetical epistemics handily reinforces the shift towards managerialism at all levels of the system managers can more easily use figures which are thin whilst words are thick. 
We may see in this example a case of particular forms of knowledge seeking - public evaluation-responding to and reinforcing equally clear assumptions about the distribution and exercise of power.

We look to the literature for the ways in which knowledge content affects its power or autonomy. Whitley's comparison (Whitley 1977) of restricted and unrestricted or configurational science is important (cf. Pantin 1968). It shows how the cognitive structures of different sciences give rise to different forms of organisation and so to different degrees of cohesion and power. The arithmetical ideal and the aim of expressing theory inhibits challenge in restricted sciences such as physics, concerned with a small number of properties of objects which can be quantitatively related. The high degree of specialisation needed creates clear boundaries within these sciences, bureaucratisation in the organisation of research and success in attracting resources. Configurational sciences, such as social sciences concerned with small numbers of highly structured entities exhibiting a large number of properties, are essentially poly-paradigmatic... Their conceptual boundaries are "highly fluid and permeable. In consequence their organisation is less structured and there is greater scope for dispute and fundamental challenge." Although Whitley (1984) does not make the point directly, it can be inferred that this in turn affects their power outside their boundaries.

The "finalisation" thesis of van den Daele et al. (1977) identifies three phases of discipline development: the exploratory, pre-or polyparadigmatic phase, the phase of paradigm articulation and the postparadigmatic phase. In the first and third phases problem orientation and discipline development are compatible. But when work is beginning to crystallise on the development of key theoretical models, usually the research programme is dictated by "internal" needs incompatible with external problems.

Adding to the epistemological debate about the most appropriate forms of production of knowledge intended for utilisation, as we have seen, Trist's definition of domains (1972) implied multiple reference groups; in contrast to disciplinary knowledge, socially robust forms may generate power by their appeal to wide constituencies including those holding power within client and practitioner groups. Along similar lines, Gibbons et al. (1994) claim to identify a shift from the traditional discipline-centred mode of knowledge production that they characterise as Mode 1, towards a broader conception of knowledge production described as Mode 2. In this, knowledge is generated in a context of application and addresses problems identified through continual 
negotiation between actors from a variety of settings. They imply a shift in power from disciplined based knowledge, and this thesis is reinforced by Nowotny et al. (2001).

Although the degree of change described by Gibbons et al. and Nowotny et al. could be exaggerated, this general approach, as with that of Trist, is compatible with attempts to identify power through utilisation by explaining research production in terms of the interests of at least some potential users.

\section{Modes of governmental power}

So far, the academic discussions quoted have centred on the nature of disciplinary differences, and the implications for academic status and structures. To meet the more general mandate of this paper it will be appropriate now to take the argument outside the walls of academe, and in two directions. The first issue is the extent to which governmental power is strengthened by its commissioning and use of research. The second is whether the increased connections between university and industry throws light on knowledge's potential to increase power within the private sector.

The classic and idealised models of government assume that government has its own power and power relationships and regulatory, allocative, rewarding and sanctioning functions. The simplicity of these classic assumptions has been drastically undermined in the last forty years. We accept that both science, or, more broadly, in Cronbach and Suppes' term (1977), disciplined enquiry, and government inhabit worlds and client groups, but increasingly they have been pulled into each others' orbits.

The extent to which governmental power is strengthened by its commissioning and use of research varies according to the salience of the policy field, the nature of the subject discipline or area to be employed, the extent to which government at any particular time is committed to a display of evident rationality (Kogan and Henkel 1983, 2000), and the nature of the organizational links between government and research institutions (Gornitzka 2004). It also varies according to the nature of the receptor (Caplan 1977; Kogan and Henkel 1983). (In many countries, central government officials receive some research training). The determinant forms of knowledge may be more convincing to managers and politicians seeking certainties than will be a "softer" and less controlled form of evidence. 
As noted earlier, positivist and applied modes of research are seen as more useful to policy makers than critical, interactive and independent modes. That is why social research has lost much of its precarious hold on policy in favour of knowledge created by inspectors, other evaluators and consultants who start with the premises of policy-makers in a clear and pre-structured way (Henkel 1991). It is perhaps paradoxical that in the UK elite theoretical scientists are given important places within the allocative and honour systems. Think Tanks whose work is primarily that of policy analysis take largely existing knowledge and reshape it towards meeting problems that are perceived to be on the policy agenda. This may appeal to government more than knowledge created by academics.

Perhaps, however, a move forward from instrumental and short-term perspectives can be found in the Foresight Initiatives in various countries which demand relatively sophisticated analysis of likely trends of demand and knowledge application (Martin and Irvine 1989).

Because government works on a broad and often unmanageable canvass, the reduction of interests, and the search for simple and elegant solutions, are a major preoccupation. Otherwise it cannot meet the political agendas of ministers, or produce workable programmes that can be rendered into priorities and actions. Yet, because it must face many interests, including ministerial agendas, professions whose claims on policy-making are based on knowledge, its very organisation is tribal and multi-modal (Kogan and Henkel 1983, pp. 3). It must act through a range of modes which include both persuasion and negotiation and the coercion of law; rational discourse based on research must compete with these.

The knowledge frames used by government are unlikely to be related to academic disciplines but are more related to policy area and client groups (Kogan and Henkel 1983). In, for example, health policy making, it has been noted that "applied research might be more readily useable by a policy system than basic research, but policymakers tend to relate more willingly to natural sciences than social sciences. Research that follows priorities determined by the researchers themselves, according to the "internalist" norms of science' is more often, though not always, going to be basic. Applied research is more likely than basic research to be following an agenda driven by forces other than the scientific imperative... where such drivers and sponsors are also the most likely potential users of the research, this provides some of the circumstances that might encourage utilisation" (Buxton et al. 2002, pp. 2-3). 
There is a necessary tension, and sometimes it seems an unbridgeable gap, between policy and research, because they represent "two different cultures with different requirements" (Caplan 1977). It is not surprising, given these characteristics of government, that it uses many other forms of knowledge.

There is no simple correspondence between the nature of the problem area, the nature of the knowledge generated, and the forms of transmission and implementation that might then emerge. It is less the nature of the knowledge that is generated than the social and institutional characteristics of main players that constitute the primary factors in determining transmission and transfer (Kogan and Henkel 2000; Gornitzka 2004). All principal kinds of knowledge: positivistic, theoretical-critical and applied/action research - have a part to play in illuminating policy and practice. There are paramount needs for "useful" knowledge, but it needs to ensure that the knowledge and concepts on which it is based are strong. Certain kinds of knowledge are particularly useful at particular levels of systems. But, again, such associations should not be regarded as iron clad.

Examples of socially robust and persuasive forms of soft knowledge that have penetrated policy are not difficult to find. Reflective thinking on gender and ethnic issues has affected current social and employment policies and practices. Some of this work is rooted in sociological, psychological, anthropological and legal studies, although its initiation and impact resulted as much from its connection with the remedy of perceived injustice as to its research qualities and content.

Another example is the critique of knowledge production and power relationships advanced in the sociology of knowledge. It must have contributed to the reduction of the status of the university as a protected and specialist institution and the sapiential authority of the professariat. From the argued positions thus set up it was easier to give a stronger place for junior staff, students and external client groups in the governance of the university.

Thus, it need not be the content of the research, or even its truth, that counts. 'Successful' social research well matches the intelligent wisdom of its time. If it is wisdom that accords with the views of those currently in power then it will certainly be listened to. It has to wait for the political agenda to move in its favour. Social and distributive issues are bound to depend on political evaluations for their pursuit in action.

Some systematic analysis of policy and practice impacts come from the fields of health and social services where researchers (Buxton and Hanney 1994) identified payback from research from a study of eight 
cases ranging from heart transplants to social care management. They concluded that a number of the studies appeared to have had a direct and significant impact on policy and executive decisions, for example in care management legislation and funding of heart transplants. Other studies became part of a body of evidence that led to clinical guidance. But the case studies also identified research that was largely ignored in the policy debate. The list of factors identified as being associated with high pay-back emphasised the importance of recruiting user interest. They included: continuing support from customers; liaison with stakeholders; appropriateness and quality of research; brokerage; appropriate dissemination. These all rested on forms of persuasiveness. The process of transmission need not be predictable but be "percolative" or "contaminative" or rely on "illumination". (Weiss 1977).

A general account of changing policy moods (Wirt 1983) depicts a cyclical process in which public services might be set up and institutionalised so that power is exercised through dominant professions until the laity - politicians, interest and client groups- become dissatisfied and take power away from them. But, before long, replacement policies lead to new forms of professionalisation and institutionalisation which perhaps a generation later will become challenged in their turn.

A UK example is of the treatment of educationally impaired children. Under the 1944 Education Act, 10 forms of "handicaps" were identified, and specialist schools and staff created to attend to them. But with the Warnock report (1982) and subsequent legislation, these categories were swept away in favour of generic "statementing" and instead a whole new profession of special educational needs set up. With this came new terminologies, new assumptions about the best ways of meeting needs, new legal stipulations and, of course, texts and training sequences. Their work has been called the only growth sector within education in the UK.

A similar example might be the changing fortunes of public policies in the field of positive discrimination - the first phase being that of "colour blind" neglect, followed by a plethora of rules and legislation creating a race relations and anti-discrimination profession, and that to some extent followed by a reaction to these new forms of professional power, albeit reinforced by external reference groups. The knowledge backing each of these policy phases will lie in the ability to identify different forms of action programmes. On those presumed abilities, both professional and legal determinism have been based. As the assumed knowledge base has changed so has the power derived from it. 
Correspondences between different phases of policy development and knowledge styles have been noted.

Caplan (1977) in a study of 204 federal policymakers, noted how the decision making orientations of $70 \%$ of them could be divided between clinical, academic and advocacy modes. Whilst the first group gathered information so that they could make an unbiased diagnosis of the policy issues, of both the internal logic and from the external logic, of political and social ramifications, of the problem, the academics were concerned mainly with the internal logic. Those with an advocacy orientation used research opportunistically and sometimes to substantiate a case primarily based on political considerations. Their perspective was almost wholly external.

As industry-university relations grow, various boundaries are in the process of collapsing. The boundaries between the regimes of internalist science and those of social robustness are thought to be more permeable and there are emerging organizational structures that crosscut them. "For example, there is much empirical data to support the view that scientists themselves in some fields (e.g., life sciences), not to mention university presidents, are deeply enmeshed in the world of the private marketplace, sitting on the boards of companies, and shaping conceptions of "social robustness."...the last quarter century has witnessed dramatic expansions in the intensity and variety of university relationships". In the 1990s, "high impact patents and highly cited publications became increasingly complementary and high impact patenting is also positively associated with high volume publications... Highly fertile patents, however, appear to be associated with increases in both the volume and impact of published findings." (Owen-Smith 2003) Indeed, even in their traditional capacity as academic scientists, many are involved in policymaking entities in defining critical fields for funding in terms of societal need. Conversely, actors generally identified with the world external to the university (e.g., representatives of business and industry), are often very much involved in defining what fields of science are valued within the academy, through institutional boards of various kinds (e.g., advisory boards of academic colleges and departments) as well as in research review panels in federal agencies (e.g., the National Science Foundation in the US and UK research councils).

Those who cross the boundaries may secure legitimacy because of social and economic usefulness. These efforts would still have to secure scientific legitimacy if they wanted them to be scientifically acceptable. Those who cross the boundary may gain political support for their 
academic work and their institutions from those powerful in industry and commerce, as well as governments anxious to encourage such links. How far the power generated from working on particular commercial or industrial problems is converted into more general political power would be an important area of study. Would it then remain as power generated by knowledge or rather from the willingness to apply ability and skills to someone else's concerns?

\section{Factors affecting nature of power patterns}

\section{Sponsorship}

We can now turn to identify those elements of research initiation and control that create power patterns which might frame knowledge creation, and the extent to which sponsors set or influence the setting or objectives. First, there is the nature of the sponsorship. Some knowledge creation is free of external sponsorship but this is increasingly unusual. Perhaps it may be said to exist in those subject areas, mainly the humanities and social sciences, where academics are on tenure and require no more than a good library and a computer to produce a solitary or even a group work. Some mathematicians and philosophers may require even less - a pencil, note paper and a glass of water. In the sciences and technologies, advancement of knowledge usually requires money for equipment, materials and technical back-up. And certain types of social science depend on external funding.

In securing sponsorship, academics may submit to highly prescriptive requirements on the objectives and forms of outcome of a project, as when receiving resources from a government department or private firm. Accountability measures can be tight. Publication may be restricted. Such prescriptive terminology as 'deliverables' or 'milestones' can reduce academics to product makers. It is unlikely that the sponsors will seek to dictate the methods used, though that can happen in the social sciences when sensitivities or ethical issues arise in approaching and working with particular subject groups. Increasingly, too, research is driven by market considerations.

In some countries, but not all, researchers look for funds from private foundations whose demands on the objectives and forms of outcome of a project, once funded, are likely to be non-existent or minimal. In the past, in the UK, the research councils were also regarded as a source of independent funding, although they varied: the old UK 
Agricultural Research Council acted virtually as the research arm of the Ministry of Agriculture; we have similar recent evidence from Norway (Gornitzka 2004). They increasingly have moved from the responsive to the initiatory mode, and are prescriptive about, for example, researcher contact with user groups.

But where funding sponsorship has become more assertive on objectives and forms of outcome have methods or epistemic characteristics been affected? Has there been 'epistemic drift' (Elzinga 1985)? For the most part, apparently not (see our studies of the Foresight Initiative (Henkel et al. 2000 and Henkel 2000) on academic identities). It would be surprising if they had, since sponsors sponsor research to create knowledge they cannot create themselves. Methods of enquiry remain in the hands of the scientists, and often government will accept objectives proposed to them (Gornitzka 2004).

\section{Institutional models}

We can note several models of the relationships that convert forms of sponsorship into institutional formats. The autonomous individualistic model would cover the minority of academics who have been able to escape the institutional coop, perhaps by virtue of distinction, and to live perhaps on free grants but within institutional protection. The autonomous collegial model assumes a group of practitioners who act to ensure their collective standards, by enforcing admission criteria; they share certain resources, but will not exercise control, within broad limits, over the nature or volume of individual work. The managed model obtains in the private sector, and in some in-house units depending heavily on external sponsorship. The partnership model where academics and industry reach agreements on quids for quos.

These institutional ecologies may be both the products and the originators of particular power-knowledge mixes. The capacity to earn or fail to earn different degrees of academic freedom will depend on various mixes of distinction and utility. The outcomes of the different forms are not easy to determine and differentiate. Power derived from teaching or research excellence may be enhanced by autonomy, but, equally, excellent research may derive from tightly managed centres. The power derived from perceived relevance is clearly demonstrable in some areas of technology, including clinical sciences, and economics. 


\section{Nature of resource required}

There is some literature on the effects of size of unit on both research functioning and economies of scale (e.g., Johnston 1993; Kyvik 1991, 1993). As far as institutional size is concerned, the jury is out on the economies of scale which are believed to level out as costs of co-ordination, particularly in multi-campus sites, increase with size. It is assumed, at least by government agencies, and some megalomaniac heads of institutions, that quality follows size, though the reverse has often been true. (Consider the size of the University of Manchester between the wars which housed both Rutherford and Narnier). In the USA, the 'best' include both very large and medium size institutions.

\section{Stage of finalisation}

It is tautologically evident that work which has reached its final form is more likely to secure both internal and external power than that which is still struggling to clarify its objectives, boundaries and methods. At the intermediate stages, both objectives and methods may be less open to pressure or negotiation.

\section{Conclusion}

Few generalisations in this area are completely true or false. There remain academic groups who pursue internalist philosophies and practices in the certified surety that these remain the right way to advance knowledge. For the most part, they secure the best academic prizes and the most esteem which are cashable as grants, prestigious academic posts, and in some subject areas, support and prestige in the outside world. At the same time, we have to note how some of the less rigorous academics have made their way into political influence by virtue of their communicativeness and perceived utility. Thus we do right in trying to specify and generalise the powerknowledge nexus, but remain tentative about any generalisation derived from doing so.

In this paper, it has been possible to relate dimensions of different kinds of power to different forms of knowledge. We have noted how the classic 'hard' forms of science have sustained their capacity to generate 
autonomy and power within academe by virtue of their cognitive selfcontaindeness and exclusivity. In parallel to them, softer forms of knowledge gain power by persuasiveness and social utility or "social robustness". Knowledge, however, that gains power by virtue of its "social robustness" or relevance to the external world may not have that power translated into credibility and influence within the social community of science. Whitley (1984) points out that configurational sciences, such as social sciences concerned with small numbers of highly structured entities exhibiting a large number of properties, are essentially poly-paradigmatic and their conceptual boundaries are "highly fluid and permeable. In consequence their organisation is less structured and there is greater scope for dispute and fundamental challenge." This must surely make them less convincing to policy-makers.

"Hard" science gains power in the wider social and political world and, increasingly, in the world of industry by virtue of its contributions beyond its own specialist boundaries. May it also be possible that it gains appeal, first, because of its capacity to tackle visible and practical problems such ill-health or the provision of energy but also because it deals in conceptually difficult knowledge of which the lay person can be only the respectful observor? However, fluidity is everywhere and this may be changing as informed or concerned lay people gain increasing access to scientific arguments and are prepared to engage in them, within Nowotny et al.'s "agora" - the marketplace.

Neither is guaranteed power in the polity where ordinary knowledge may be preferred to the products of more disciplined enquiry.

Although, then, there are relationships between the cognitive and institutional aspects of knowledge and power, they have the status of tendencies and it is not possible to assume determinant contingent relationships between them.

There is a large agenda to be pursued in this area of enquiry. In particular, the extent to which power gained by academics as they cross the boundary to work with industry is to be examined. Is this power restricted to the impact of the knowledge brought to bear on industrial problems? Or does it convert to more general political power?

\section{Note}

"This paragraph owes much to an anonymous reviewer. 
MAURICE KOGAN

\section{References}

Becher, T. (1989). Academic Tribes and Territories. Buckingham: Open University Press.

Biglan, A. (1973). 'Relationships between subject matter characteristics and the structure and output of university departments', Journal of Applied Psychology 57 (3), 204-213

Bourdieu, P. (1975). 'The specificity of the scientific field and the social conditions of progress', Social Sciences Information 14 (6), 19-47.

Braxton, J.M. and Hargens, L.L. (1996). 'Variations among academic disciplines: analytical frameworks and research', in Smart, J. (ed.), Higher Education Handbook of Theory and Research, vol. XI, New York: Agathon Press, pp. 1-46.

Buxton, M., Gonzalez-Block, M.-H, and Kogan, M., 'The Utilisation of Health Research in Policy-Making: Concepts, Examples, and Methods of Assessment'. HERG Research Report No. 28 October 2002.

Caplan, N. (1977). 'The use of social research knowledge at the national level', in Weiss, C.H. (ed.), Using Social Research in Public Policymaking. Lexington, DC: Heath.

Lindblom, C.E. and Cohen, D. (1979). Usable Knowledge: Social Science and Social Problem Solving. New Haven: Yale University Press.

Cronbach, L. and Suppes, P. (eds.) (1969). Research for Tomorrow's School. A Disciplined Enquiry for Education.

Elzinga, A. (1985). 'Research, bureaucracy and the drift of epistemic criteria' in Wittrock, B. et al. (eds.), The University Research System, the Public Policies of the Homes of Scientists. Stockholm: Almqvist and Wicksell.

Elzinga, A. (1987). 'Internal and external regulatives in research and higher education systems.' in Premfors, R. (ed.), Disciplinary Perspectives on Higher Education and Research. Report No. 37. Stockholm: Almqvist and Wicksell.

Foucault, M. (1977). Power/Knowledge. New York: Pantheon.

Gibbons, M. et al. (1994). The New Production of Knowledge. London: Sage.

Gornitzka, A. (2004). Science, Clients and the State: A Study of Scientific Knowledge Production. Enschede: CHEPS/UT.

Henkel, M. (1991). Government, Evaluation and Change. London: Jessica Kingsley Publishers.

Henkel, M. (1998). 'Evaluation in Higher Education. Conceptual and epistemological foundations' European Journal of Education 33 September.

Henkel, M. (2000). Academic Identities and Policy Change in Higher Education. London: Jessica Kingsley Publishers.

Henkel, M., Hanney, S., Vaux, J. and Von Walden Laing, D. (2000). Academic Responses to the UK Foresight Initiative. Research Report. Uxbridge: CEPPP, Brunel University.

Isaac, J. (2004). 'Conceptions of power' in Hawkesworth, M. and Kogan, M. (eds.), Routledge Encyclopaedia of Government and Politics, 2nd Edition, London: Routledge, pp. 57-69.

Johnston, R., (ed.), (1993). 'The Effects of Resource Concentration on Research Performance.' Canberra: National Board of Employment, Education and Training.

Kogan, M. and Henkel, M. (1983). Government and Research. London: Heinemann

Kogan, M. and Henkel, M. (2000). 'Getting inside: policy reception of research', in Schwarz, S. and Teichler, U. (ed.), The Institutional Basis of Higher Education Research. Chapter 2. Dordrecht: Kluwer. 
Kuhn, T.S. (1962). The Structure of Scientific Revolutions. Chicago: Chicago University Press.

Kyvik, S. (1991). Productivity in Academia. Scientific Publishing at Norwegian Universities. Oslo: Norwegian University Press.

Kyvik, S. (1993). 'Academic Staff and Scientific Production', Higher Education Management Vol 5.2, July 1993.

Mendelsohn, E., Weingart, P. and Whitley, R. (eds.) (1977). The Social Production of Scientific Knowledge Vol.1. Dordrecht: D. Reidel Publishing Company.

Merton, R.K. (1957). Social Theory and Social Structure Glecoe Ill.

Mulkay, M.J. (1977). 'Sociology of the scientific research community', in SpiegelRosing, I. and de Solla Price, D. (eds.), Science, Technology and Society. London: Sage.

Mulkay, M.J. (1979). Science and the Sociology of Knowledge. George Allen and Unwin.

Nagel, E. (1961). The Structure of Science. Problems in the Logic of Scientific Explanation. London and Henley: Routledge and Kegan Paul.

Nowotny, H., Scott, P. and Gibbons, M. (2001). Rethinking Science: Knowledge and the Public in an Age of Uncertainty. Oxford: Polity Press.

OECD (1995). Educational Research and Development. Trends, Issues and Challenges. Paris: OECD.

Owen-Smith, J. (2003). 'Complements and Substitutes: The Changing Institutional Environment of Public , and Private Science.' Draft paper presented at the SCANCOR Conference on Universities and the Production of Knowledge, Stanford University, April 2003.

Polanyi, M. (1962). 'The Republic of Science: Its political, and economic theory', Minerva, $1(1)$.

Philp, M. (1984). 'Authority' in Kuper, A. and J. The Social Science Encyclopaedia, pp. 55-56, London: Routledge.

Popper, K.R. (1972). The Logic of Scientific Discovery. London: Hutchinson.

Rein, M. (1983). From Policy to Practice. New York: Macmillan.

Rip, A. 'A Cognitive Approach to the Relevance of Science.' Social Science Information. 36(4), pp. 615-640.

Storer, N.W. (1967). 'The hard sciences and the soft: some sociological observations. Bulletin of the Medical Library Association 55(1): 75-84.

Storer, N.W. (1972). 'Relations among scientific disciplines', in Nagi, Corwin, S.Z. and R.G. (eds.), The Social Contexts of Research. New York: Wiley, pp. 229-68.

Storer, N.W. and Parsons, T. (1968). 'The disciplines as a differentiating force', in Montgomery, E.B. (ed.), The Foundation of Access in Knowledge - A Symposium. Syracuse: Division of Summer Sessions, Syracuse University.

Trist, (1972). 'Types of output mix of research organisations and their complementarity', in Cherns A.B. et al. (eds.), Social Science and Government, Policies and Problems. Tavistock Publications.

Van den Daele, W., Krohn W. and Weingart, P. (1977). 'The political direction of scientific Development', in Mendelsohn, E., Weingart, P. and Whitley, R.D. (eds.), The Social Production of Scientific Knowledge, vol. 1. Dordecht: D. Reidel Publishing Co.

Warnock Report (1978). Meeting Special Educational Needs: The Report of the Committee of Enquiry into Education of Handicapped Children and Young People. London: HMSO. 
Weiss. C.H. (1977). Using Social Research in Public Policymaking Lexington, DC: Heath, pp. 183-197.

Weingart, P. (1977). 'Science policy and the development of science', in Blume, S. (ed.), Perspectives in the Sociology of Science. Chichester: John Wiley \& Son.

Weiss, C. (1980). Social Science Research and Decision-Making. Columbia: Columbia University Press.

Weiss, C. (1982). 'Policy research in the context of diffuse decision-making', in Kosse G. (ed.), Social Science Research and Public Policy-making. London: NFER-Nelson.

Whitley, R.D. (1977). 'Changes in the social and intellectual organisation and social organisation of the sciences' in Mendelsohn, E., Weingart, P. and Whitley, R. op.cit.

Whitley, R.D. (1984). The Intellectual and Social Organization of the Sciences.

Wirt, F. (1981). 'Professionalism and political conflict: A developmental model', Journal of Public Policy, 1, Part 1. 
Copyright of Higher Education is the property of Kluwer Academic Publishing and its content may not be copied or emailed to multiple sites or posted to a listserv without the copyright holder's express written permission. However, users may print, download, or email articles for individual use. 